\title{
Structural Elucidation of Isocyanate-Peptide Adducts Using Tandem Mass Spectrometry
}

\author{
Justin M. Hettick, Tinashe B. Ruwona, and Paul D. Siegel \\ Health Effects Laboratory Division, Centers for Disease Control and Prevention, National Institute for \\ Occupational Safety and Health, Morgantown, West Virginia, USA
}

\begin{abstract}
Diisocyanates are highly reactive chemical compounds widely used in the manufacture of polyurethanes. Although diisocyanates have been identified as causative agents of allergic respiratory diseases, the specific mechanism by which these diseases occur is largely unknown. To better understand the chemical species produced when isocyanates are reacted with model peptides, tandem mass spectrometry was employed to unambiguously identify the binding site of four commercially-relevant isocyanates on model peptides. In each case, the isocyanates react preferentially with the N-terminus of the peptide. No evidence of side-chain/ isocyanate adduct formation exclusive of the N-terminus was observed. However, significant intra-molecular diisocyanate crosslinking was observed between the N-terminal amine and a side-chain amine of arginine, when Arg was located within two residues of the N-terminus. Addition of multiple isocyanates to the peptide occurs via polymerization of the isocyanate at the N-terminus, rather than via addition of multiple isocyanate molecules to varied residues within the peptide. The direct observation of isocyanate binding to the N-terminus of peptides under these experimental conditions is in good agreement with previous studies on the relative reaction rate of isocyanate with amino acid functional groups. (J Am Soc Mass Spectrom 2009, 20, 1567-1575) (C) 2009 Published by Elsevier Inc. on behalf of American Society for Mass Spectrometry
\end{abstract}

$\mathrm{D}$ iisocyanates are highly reactive chemicals widely utilized in the manufacture of polyurethane products, such as fibers, foams, insulation, and automotive products, including paints and protective coatings for truck beds. The most widely used isocyanates are the diisocyanates methylenebis(phenyl isocyanate) (MDI), toluene diisocyanate (TDI) and hexamethylene diisocyanate (HDI). TDI is often utilized in industrial applications in $80 / 20$ and $65 / 35$ mixtures of the 2,4- and 2,6-TDI isomers. Globally, TDI accounts for $34 \%$ of the isocyanate market [1]. Diisocyanate exposure results in sensitization and asthma, contact dermatitis, and hypersensitivity pneumonitis [2]. Diisocyanateinduced asthma in occupationally exposed worker populations is estimated to range from $5 \%$ to $30 \%$ [2-5]. The isocyanate $(\mathrm{N}=\mathrm{C}=\mathrm{O})$ functional group may react with water to form amines, with alcohols to form urethanes, with amines to form ureas, with carboxylic acids to form amides, and following hydrolysis, with other isocyanates to form dimers and trimers. Previous studies $[6,7]$ present strong evidence that diisocyanates bind to such proteins as albumin and keratins in the airway. Furthermore, some occupational tasks, such as paint mixing/spraying and production of composite wood products, result in significant diisocyanate der-

Address reprint requests to Dr. J. M. Hettick, Centers for Disease Control and Prevention, National Institute for Occupational Safety and Health, Health Effects Laboratory Division, MS L-2040, 1095 Willowdale Road, Morgantown, WV 26505, USA. E-mail: jhettick@cdc.gov mal exposures $[8,9]$ which may also lead to the development of asthma-like symptoms.

Although several protein targets of diisocyanates in vivo have been identified, the underlying antigenic forms of the diisocyanate are, as yet, unknown [10-12]. The diverse functional groups present in proteins including amines, amides, thiols, alcohols, and carboxylic acids present a large number of potential reaction sites for the isocyanate. However, previous studies have suggested that under physiologic conditions, these are limited to $\mathrm{N}$-terminal $\alpha$-amines, the sulfhydryl group of cysteine, the hydroxyl groups of serine and tyrosine, the $\varepsilon$-amine of lysine, and the secondary amine of the imidizole ring of histidine [13].

Tandem mass spectrometry, in particular collision induced dissociation (CID) of $[\mathrm{M}+2 \mathrm{H}]^{2+}$ ions produced via electrospray ionization (ESI) [14-17] is a powerful technique for the determination of not only primary sequence in peptides [18], but also post-translational modification [15] or chemical adduction. In this study, we have applied CID on a high-resolution quadrupole time-offlight (qTOF) mass spectrometer [19] to characterize the adducts produced by the reaction of four commercially available bioactive peptides with four industrially relevant mono- and diisocyanates in an effort to (1) determine the number, chemical identity, and relative abundance of reaction products observed, and (b) identify the specific binding site of the isocyanate within the peptide. In particular, we have studied the adducts formed by 2,4- and 2,6-TDI because of the widespread 
<smiles>Cc1ccc(N=C=O)cc1N=C=O</smiles>

toluene-2,4-diisocyanate (2,4-TDI) $m / z=174.0429$<smiles>Cc1c(N=C=O)cccc1N=C=O</smiles>

toluene-2,6-diisocyanate $(2,6-T D I) ~ m / z=174.0429$<smiles>Cc1c(N)cccc1N=C=O</smiles>

3-isocyanato methylaniline

(TAI) $m / z=148.0634$

Figure 1. Structures of the isomers of toluene isocyanate, toluene diisocyanate and a hydrolysis product.

use of these chemicals in manufacturing, and their well-documented health effects. Due to the possibility of complex reaction products including inter- and intramolecular crosslinking with the diisocyanates, we have also evaluated the binding chemistry of the monoisocyanate analogues of 2,4- and 2,6-TDI, paratoluene isocyanate (PTI) and ortho-toluene isocyanate (OTI).

\section{Experimental}

\section{Reagents}

Unless otherwise specified, all reagents were acquired from Sigma-Aldrich (St. Louis, MO, USA) and used without further purification. Formic acid (99.5\%) was of mass spectrometry grade and acetonitrile and acetone were HPLC-grade. Ortho-toluene isocyanate (OTI), para-toluene isocyanate (PTI), 2,4-toluene diisocyanate (2,4-TDI, and 2,6-toluene diisocyanate (2,6-TDI) were dissolved in HPLC-grade acetone. The peptides leucine-enkephalin (Leu-enk, YGGFL), angiotensin I (DRVYIHPFHL), Substance P-amide (RPKPQQFFGLM-NH ${ }_{2}$ ), and fibronectin- adhesion promoting peptide (FAPP, WQPPRARI) were dissolved in $18 \mathrm{M} \Omega$ distilled deionized water (DDI) produced by a Millipore Synthesis A-10 (Billerica, MA, USA).

\section{Preparation of Isocyanate-Peptide Adducts}

Stock peptide solutions were prepared in DDI at a concentration of $0.5 \mathrm{mg} / \mathrm{mL}$. Solutions of each of the four isocyanates were freshly prepared in $1 \mathrm{~mL}$ HPLCgrade acetone and infused at a 1:1 mol ratio into each peptide solution at a rate of $1.2 \mathrm{~mL} / \mathrm{h}$ using a syringe pump (model 100; KD Scientific Inc., Holliston, MA, USA) with constant stirring. Reactions were carried out at room temperature in a chemical fume hood, and allowed to stir for 15 min following completion of the infusion. Peptide-isocyanate adduct solutions were filtered using $0.45 \mu \mathrm{m}$ filters (Millipore, Billerica, MA, USA) and stored at $-20^{\circ} \mathrm{C}$ until analysis.

\section{Mass Spectrometry}

Aliquots of each peptide adduct solution were diluted 50:1 in 50/50 0.1\% formic acid/HPLC-grade acetonitrile, yielding a final solution concentration of all peptideNCO species of $\sim 100 \mathrm{pmol} / \mu \mathrm{L}$. Samples were infused at a rate of $5 \mu \mathrm{L} / \mathrm{min}$ to a Micromass QTOF2 (Waters Corp., Milford, MA, USA) quadrupole time-of-flight mass spectrometer operated in positive electrospray (+ESI) mode. Sample analysis was performed at a capillary voltage of $2.5 \mathrm{kV}$ with dry $\mathrm{N}_{2}$ desolvation gas (NitroFlowLab; Parker Hannifin Corp., Haverhill, MA, USA) at a flow rate of $400 \mathrm{~L} / \mathrm{h}$ and a temperature of $150{ }^{\circ} \mathrm{C}$. Ultra High Purity (UHP) Argon was used as a collision gas at collision energies of $5 \mathrm{eV}$ (MS analysis) and 25-30 eV (MS/MS analysis). For peptide sequencing, the doubly charged $[\mathrm{M}+2 \mathrm{H}]^{2+}$ ion was selected by $\mathrm{MS}^{1}$, with the exception of Leu-enkephalin (the [M + $\mathrm{H}^{+}$ion was selected). The collision energy was set independently for each peptide to yield optimal relative abundance of sequence-specific fragment ions. Postacquisition mass spectral charge deconvolution was performed with the "MaxEnt3" algorithm in the ProteinLynx 4.1 software suite (Waters Corp., Milford, MA, USA). The mass spectrometer was externally calibrated over the range 70-1570 $\mathrm{u}$ using the CID fragment ion mass spectrum of $[\mathrm{Glu}]^{1}$-fibrinopeptide B (EGVNDNEEGFFSAR) $[\mathrm{M}+2 \mathrm{H}]^{2+}$ ions acquired at a collision energy of $35 \mathrm{eV}$.

Table 1. Relative ion intensities of ortho- and para-toluene isocyanate/peptide reaction products

\begin{tabular}{llccc}
\hline \multicolumn{1}{c}{ Peptide } & \multicolumn{1}{c}{ Sequence } & M & M + OTI & M + PTI \\
\hline \hline Leu-enk & YGGFL & 100 & 4.7 & 1.3 \\
Angiotensin I & DRVYIHPFHL & 13 & 100 & 18 \\
FAPP & WOPPRARI & 26 & 31 & 100 \\
Substance P & RPKPQQFFGLM-NH & 0.35 & 100 & 32 \\
\hline
\end{tabular}


Table 2. Relative ion intensities of 2,4-toluene diisocyanate/peptide reaction products

\begin{tabular}{|c|c|c|c|c|c|c|}
\hline Peptide & Sequence & $\mathrm{M}$ & $\mathrm{M}+\mathrm{TDI}^{*}$ & $\mathrm{M}+\mathrm{TDI}$ & $\mathrm{M}+2 \mathrm{TDI}^{*}$ & $2 \mathrm{M}+\mathrm{TDI}$ \\
\hline Leu-enk & YGGFL & 100 & 3.4 & - & 0.89 & - \\
\hline Angiotensin I & DRVYIHPFHL & 83 & 100 & 29 & 47 & 23 \\
\hline FAPP & WQPPRARI & 100 & 13 & - & 5.5 & 9.4 \\
\hline Substance P & RPKPQQFFGLM-NH ${ }_{2}$ & 33 & 17 & 100 & 9.6 & 50 \\
\hline
\end{tabular}

*Hydrolysis product (amine group at either position 2 or 4).

\section{Results and Discussion}

\section{MS Analysis of Isocyanate/Peptide Reaction Products}

Four bioactive peptides were chosen for analysis (Leu-enk, angiotensin I, FAPP, and Substance P-amide) and reacted with two monoisocyanates (OTI and PTI) and two diisocyanates (2,4-TDI and 2,6-TDI). Structures and mass-to-charge data for each of these isocyanates is presented in Figure 1. The four peptides were chosen because they contain putative reactive amino acid residues in varied locations (e.g., N-terminus, internal, C-terminus). The resulting reaction products were analyzed by high-resolution qTOF-MS. The relative abundance and accurate mass $( \pm 20 \mathrm{ppm})$ of the major reaction products was measured in qTOF-MS mode and the identity and relative intensity of the observed reaction products are listed in Tables 1, 2, and 3. The only reaction products observed for the monoisocyanates OTI and PTI (Table 1) were unreacted peptide $[\mathrm{M}+2 \mathrm{H}]^{2+}$ and the product formed by addition of one isocyanate to the peptide $[\mathrm{M}+\mathrm{NCO}+2 \mathrm{H}]^{2+}$ $(+133.0528 \mathrm{u})$. For Leu-enk, angiotensin I, and Substance $\mathrm{P}$, the OTI adduct was two to five times more abundant than the PTI adduct.

The products of the reaction of peptides with the diisocyanate species 2,4- and 2,6-TDI were significantly more varied. A number of reaction products were observed (see Tables 2 and 3 ) including the anticipated mono-substituted $\left[\mathrm{M}+\mathrm{dNCO}^{*}+2 \mathrm{H}\right]^{2+}(+148.0634 \mathrm{u})$ product. (The asterisk $\left(^{*}\right)$ indicates the diisocyanate product that has undergone hydrolysis at one isocyanate, see Figure 1). TDI hydrolyzes rapidly to a diamine in aqueous solution, with a half life of 5 to $30 \mathrm{~s}[20,21]$. Consequently, the $+174.0429 \mathrm{u}[\mathrm{M}+\mathrm{dNCO}+2 \mathrm{H}]^{2+}$ adduct is not observed unless the second isocyanate reacts at another site within the peptide to form an intramolecularly crosslinked species. In the case of Substance $\mathrm{P}$, this intramolecular crosslinked species was the dominant reaction product, whereas it was only a minor reaction product (ca. 30\% relative abundance) for angiotensin I. Intramolecular crosslinking is not observed for leu-enk or FAPP, neither of which has residues with side-chain amines near the N-terminus. Adduction of two hydrolyzed TDI molecules, [M + $\left.2 \mathrm{dNCO}^{*}+2 \mathrm{H}\right]^{2+}$, was observed in low relative abundance, as was intermolecular crosslinking of two peptides via TDI, $[2 \mathrm{M}+\mathrm{dNCO}+2 \mathrm{H}]^{2+}$. Sabbioni and coworkers [13] suggested in 2001 that both isocyanate moieties of a diisocyanate would not react at the same time with one or more proteins (e.g., formation of [M + $\mathrm{dNCO}+2 \mathrm{H}]^{2+}$ and $[2 \mathrm{M}+\mathrm{dNCO}+2 \mathrm{H}]^{2+}$ should not be observed). However, under the conditions employed here, these products are formed, and in the case of Substance $\mathrm{P}$, such crosslinking represents the dominant reaction product(s).

Addition of a second TDI molecule to the peptide is the result of polymerization of two diisocyanates to form a dimer bound to the peptide, rather than binding of two dNCOs to two different amino acid residues (e.g., side-chain adduction). This was determined on the basis of CID data (described below), as well as the observation of two TDI molecules bound to Leuenkephalin, which has only one putative binding site, the N-terminal primary amine.

In general, we observe that isocyanates at the 2position (OTI and 2,6-TDI) are far more abundant adducts than those at the 4-position (PTI and 2,4-TDI) under the aqueous conditions employed for this study. Although the isocyanate in the 4-position is roughly four times more reactive than that in the 2-position toward alcohols (during polyurethane production) the 2-position is more reactive toward amines, in good agreement with our observations [1, 22]. A comparison of the relative reactivity of the peptides with isocyanates is difficult to make as the $\mathrm{pH}$ of non-buffered aqueous solutions will vary with the chemical nature of the peptide dissolved. Although current investigations into the effect of $\mathrm{pH}$ on isocyanate-peptide binding are underway in our laboratory, previous studies have dem-

Table 3. Relative ion intensities of 2,6-toluene diisocyanate/peptide reaction products

\begin{tabular}{|c|c|c|c|c|c|c|}
\hline Peptide & Sequence & $\mathrm{M}$ & $\mathrm{M}+\mathrm{TDI}^{*}$ & $\mathrm{M}+\mathrm{TDI}$ & $M+2 T D I^{*}$ & $2 \mathrm{M}+\mathrm{TDI}$ \\
\hline Leu-enk & YGGFL & 100 & 3.7 & - & 0.11 & - \\
\hline Angiotensin I & DRVYIHPFHL & 40 & 100 & 5.2 & 30 & 18 \\
\hline FAPP & WOPPRARI & 100 & 14 & - & 4 & 4.7 \\
\hline Substance $P$ & RPKPQQFFGLM-NH ${ }_{2}$ & 6.2 & 29 & 100 & 11 & 18 \\
\hline
\end{tabular}

*Hydrolysis product (amine group at either position 2 or 4). 
onstrated that buffers, such as phosphate and carbonate, act as competing nucleophiles in this system [23].

\section{Tandem MS Analysis of Isocyanate-Peptide Adducts}

To determine the isocyanate binding site, each peptide and its isocyanate adduct(s) was selected for sequencing by tandem mass spectrometry utilizing Ar collisioninduced dissociation in the qTOF mass spectrometer. The MS/MS spectrum of each peptide and its corresponding isocyanate adducts are presented in Figures 2, $3,4,5$, and 6 . For each peptide, the tandem mass spectra of the monoisocyanate adducts (OTI and PTI) and the diisocyanate adducts (2,4- and 2,6-TDI) were very similar in terms of $\mathrm{m} / \mathrm{z}$ and relative abundance of the observed fragment ions. For simplicity, only the fragment ion spectra of the PTI and 2,4-TDI adducts are presented here. The fragment ion mass spectra of the OTI and 2,6-TDI adducts may be found in the Supporting Information, which can be found in the electronic version of this article.

Figure 2 presents the CID fragment ion mass spectra for Leucine-enkephalin (YGGFL) and the adducts produced by reaction with PTI and 2,4-TDI. The tandem mass spectrum of unmodified Leu-enk (Figure 2a) is characterized by abundant a- and b-type fragment ions indicative of N-terminal charge retention. A few low abundance $\mathrm{y}$-type ions, indicative of C-terminal charge retention, are observed. Similarly, the fragment ion mass spectra of the peptide-isocyanate adducts (Figure $2 \mathrm{~b}$ and $\mathrm{c}$ ) are characterized by abundant $\mathrm{N}$-terminal
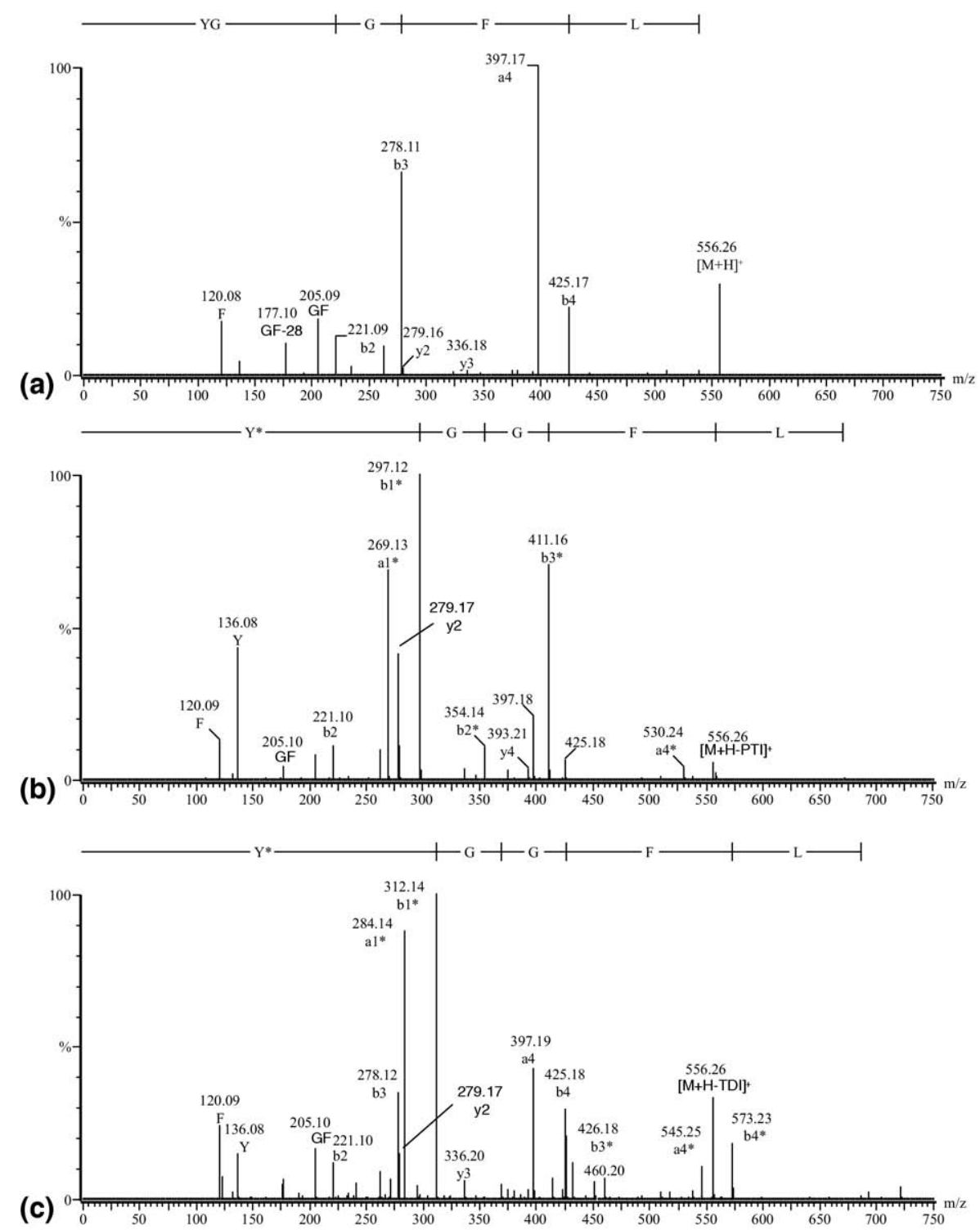

Figure 2. Selected tandem mass spectra for Leucine-enkephalin (YGGFL). (a) Unmodified peptide $\left([\mathrm{M}+\mathrm{H}]^{+} m / z=556.2766\right) ;(\mathbf{b})$ PTI adduct $\left([\mathrm{M}+\mathrm{H}]^{+} m / z=689.3294\right) ;\left(\right.$ c) $2,4-\mathrm{TDI}$ adduct $\left([\mathrm{M}+\mathrm{H}]^{+}\right.$ $m / z=704.3400)$. 

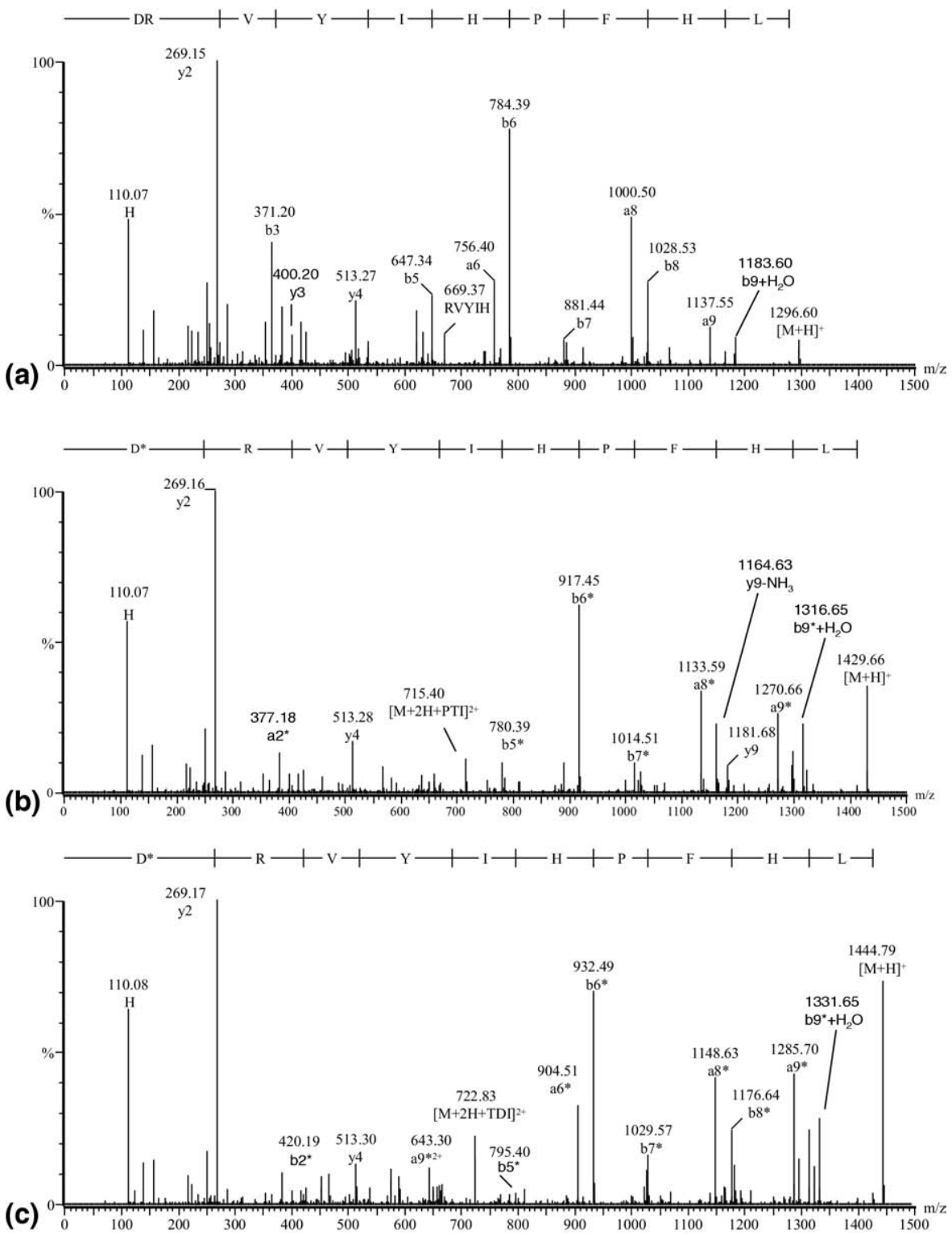

Figure 3. Selected tandem mass spectra for angiotensin I (DRVYIHPFHL). (a) Unmodified peptide $\left([\mathrm{M}+2 \mathrm{H}]^{2+} m / z=648.8463\right) ;(b)$ PTI adduct $\left([\mathrm{M}+2 \mathrm{H}]^{2+} \mathrm{m} / z=715.3728\right) ;(\mathbf{c}) 2,4$-TDI adduct ([M + $\left.2 \mathrm{H}]^{2+} m / z=722.8781\right)$.

charge retention ions. In each case, the base peak in the fragment ion spectrum is of the type $\left[b_{1}+\mathrm{NCO}^{+}\right.$ (denoted $\mathrm{b} 1^{*}$ ), which provides direct evidence that the isocyanate is bound to the N-terminal tyrosine of the peptide. Furthermore, tyrosine is the only immonium ion observed bound to the isocyanate. These immoniumisocyanate ions are useful because they provide direct evidence of isocyanate bound to a specific residue. A complete set of low abundance $\mathrm{y}_{\mathrm{n}}{ }^{+}$ions are observed; however, no ions of the type $\left[y_{n}+\mathrm{NCO}^{+}\right.$are observed, providing strong evidence that $\mathrm{NCO}$ is exclusively bound to the N-terminal tyrosine. Loss of PTI and 2,4-TDI are observed from a-, b-, and immonium ions, indicating that the urea bond formed when the isocyanate binds to the $\mathrm{N}$-terminus is labile under CID conditions. Because of this, we cannot rule out low abundance binding of NCO to other sites than the $\mathrm{N}$-terminus, however, the spectra shown herein present no evidence of such binding. A complementary nonergodic fragmentation methodology, such as electron capture dissociation (ECD) [24], could help clarify this issue by reducing small molecule losses from peptide ions, but is not available on qTOF MS instrumentation.

The CID tandem mass spectra of angiotensin I (DRVYIHPFHL) and its PTI and 2,4-TDI adducts are presented in Figure 3. The tandem mass spectrum of the angiotensin I $[\mathrm{M}+2 \mathrm{H}]^{2+}$ ion (Figure 3a) shows abundant fragmentation with both $\mathrm{N}$ - and $\mathrm{C}$-terminal charge retention, particularly for fragment ions containing histidine (e.g., $\mathrm{y}_{2}$ and $\mathrm{y}_{4}$ ). The tandem mass spectra of the isocyanate adducts (Figure $3 b$ and c) yield complete 


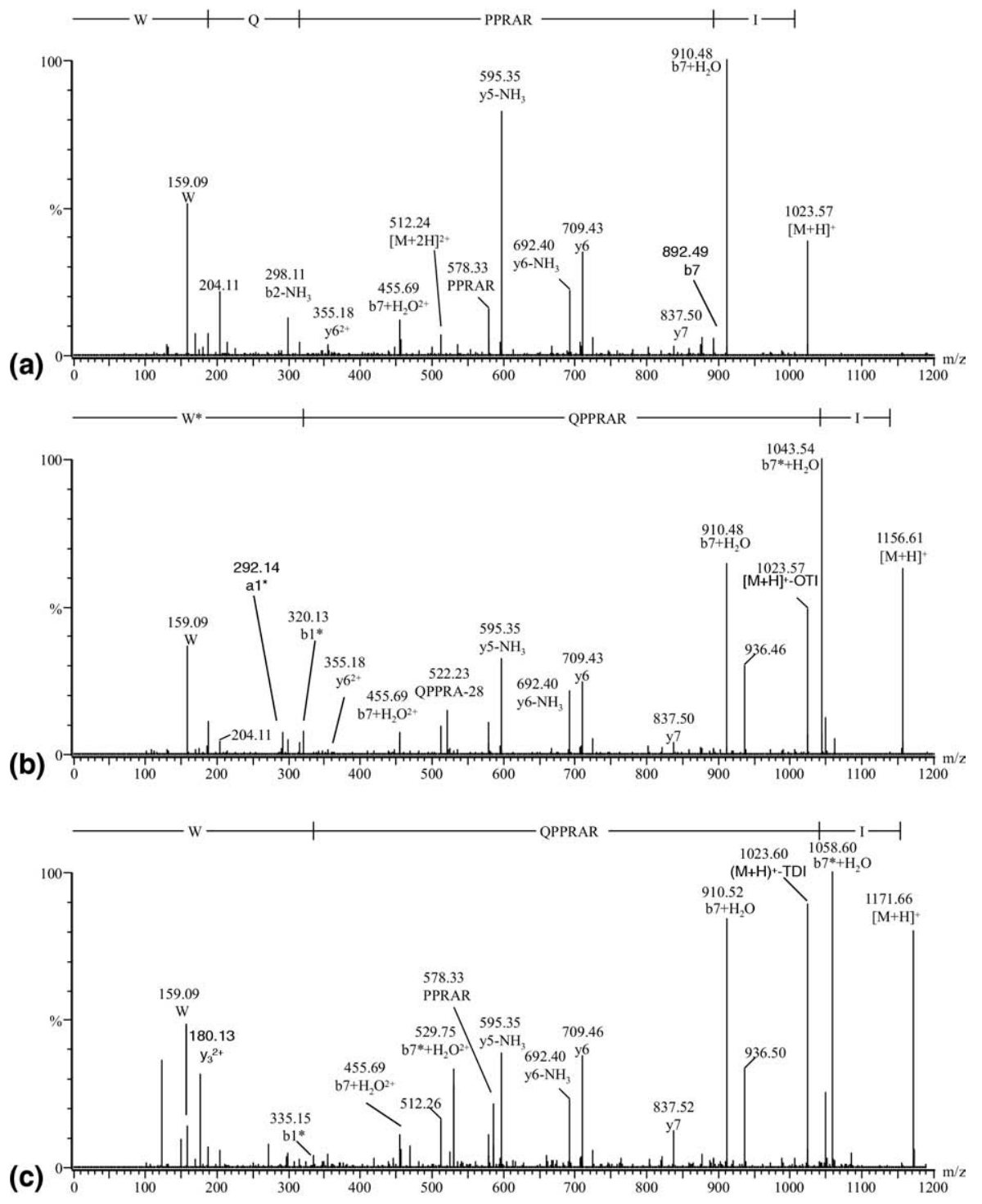

Figure 4. Selected tandem mass spectra for fibronectin adhesion promoting peptide (WQPPRARI). (a) Unmodified peptide $\left([\mathrm{M}+2 \mathrm{H}]^{2+} \mathrm{m} / \mathrm{z}=512.2960\right)$; (b) PTI adduct $\left([\mathrm{M}+2 \mathrm{H}]^{2+} \mathrm{m} / \mathrm{z}=578.8227\right)$;

(c) 2,4-TDI adduct $\left([\mathrm{M}+2 \mathrm{H}]^{2+} \mathrm{m} / \mathrm{z}=586.3280\right.$.

sequence information, demonstrating that the isocyanate has bound to the N-terminal aspartic acid residue. Isocyanate is not observed bound to any C-terminal (y-type) fragment ions, nor is it observed bound to the histidine immonium ion. Observation of the prominent $\mathrm{y}_{2}$ ion and lack of the $\left[\mathrm{y}_{2}+\mathrm{NCO}^{+}\right.$fragment ion suggests that neither the secondary amine on the side chain of histidine nor the C-terminus is reactive with isocyanate under these conditions. We conclude that isocyanate is bound to the N-terminal amine rather than the side-chain carboxylic acid of the N-terminal aspartic acid because no C-terminal binding of the isocyanate is observed in this or any other tandem mass spectra. The $\mathrm{pK}_{\mathrm{a}}$ of the aspartic acid side chain is similar to C-terminal carboxylic acids, both of which should be deprotonated at non-acid $\mathrm{pH}$, and therefore would be expected to have similar reactivity toward isocyanates.
For all four peptides examined in this study, we observe the apparent adduction of two TDI molecules $(+296.1468 \mathrm{u})$. To determine the binding site of the second TDI molecule, CID was performed on the [M + $\left.2 \mathrm{TDI}^{*}+2 \mathrm{H}\right]^{2+}$ ion of angiotensin I (supporting data). The tandem mass spectrum (in particular, observation of the $y_{9}$ ion) unambiguously identifies the binding site of the second TDI molecule as the N-terminus. This suggests that one isocyanate group of TDI binds to the $\mathrm{N}$-terminus and the second isocyanate group is hydrolyzed to the amine, which then reacts with a second TDI molecule. Thus, the two TDI molecules are polymerized at the N-terminus, rather than bound to two separate locations within the peptide.

Figure 4 presents the CID tandem mass spectra for fibronectin adhesion promoting peptide (WQPPRARI) and its PTI and 2,4-TDI adducts. The tandem mass spectrum of the FAPP $[\mathrm{M}+2 \mathrm{H}]^{2+}$ ion (Figure $4 \mathrm{a}$ ) 


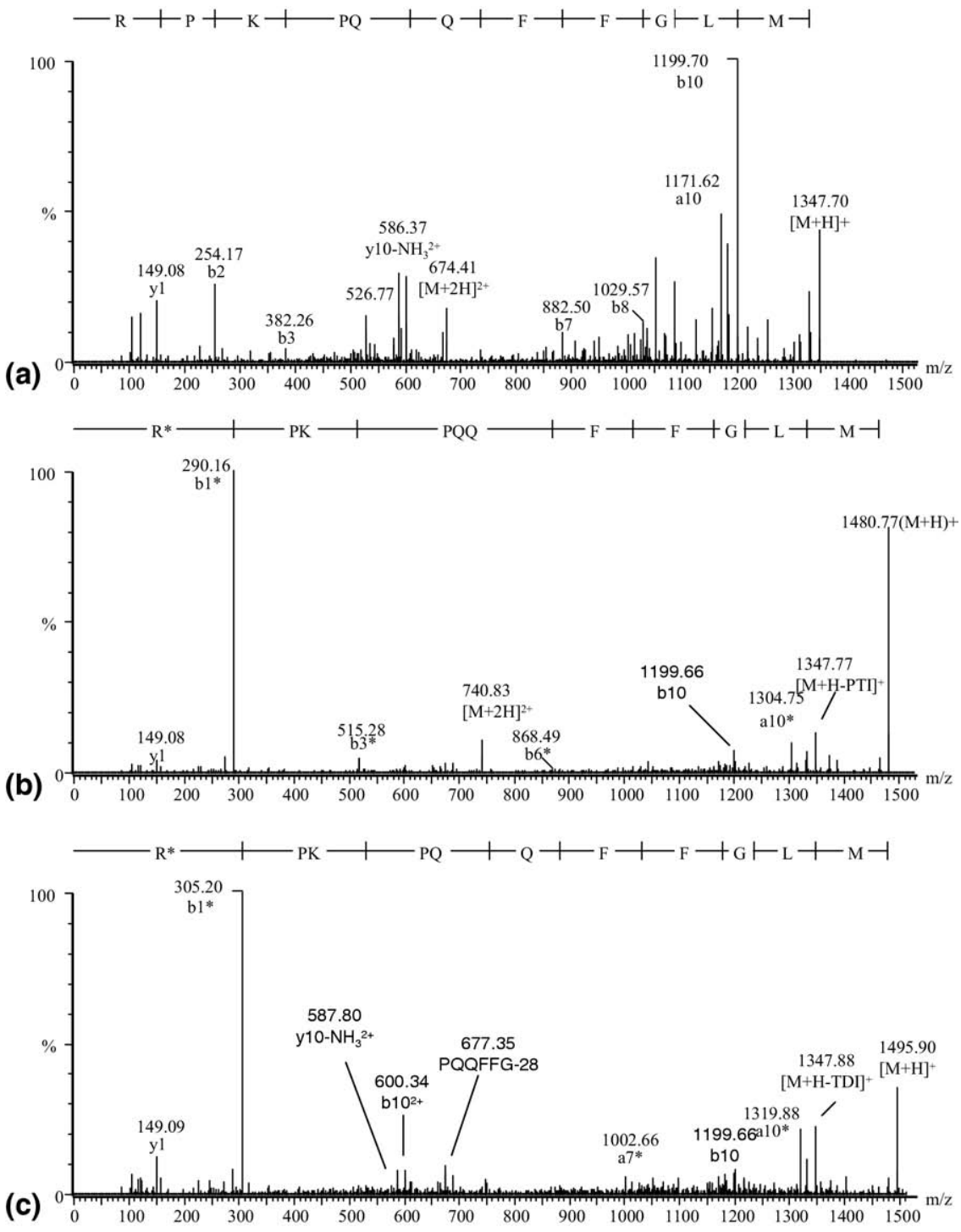

Figure 5. Selected tandem mass spectra for Substance P-amide (RPKPQQFFGLM-NH $\mathrm{N}_{2}$ ). (a) Unmodified peptide $\left([\mathrm{M}+2 \mathrm{H}]^{2+} \mathrm{m} / \mathrm{z}=674.3713\right)$; (b) PTI adduct $\left([\mathrm{M}+2 \mathrm{H}]^{2+} \mathrm{m} / \mathrm{z}=740.8981\right)$; (c) 2,4-TDI adduct $\left([\mathrm{M}+2 \mathrm{H}]^{2+} \mathrm{m} / \mathrm{z}=748.4034\right)$.

shows predominantly y-type ions, indicative of Cterminal charge retention. This is not an unexpected result, given the strongly basic residue arginine at positions 5 and 7 within the peptide. Abundant loss of $\mathrm{NH}_{3}$ from fragment ions is observed, consistent with the tandem mass spectra of other peptides containing Arg, Lys, Gln, and Asn. In addition, a strong $\left[b_{7}+\right.$ $\left.\mathrm{H}_{2} \mathrm{O}\right]^{+}$ion is observed, as has been well documented for peptides with non-C-terminal protonated side-chain residues, such as Arg, Lys, and His [25]. From the tandem mass spectrometry data (Figure $4 \mathrm{~b}$ and $\mathrm{c}$ ), the isocyanate adduct may be unambiguously assigned to the N-terminal tryptophan residue. No ions of the type $\left[\mathrm{y}_{\mathrm{n}}+\mathrm{NCO}\right]^{+}$are observed, in particular, the lack of $\left[\mathrm{y}_{2}+\right.$ $\mathrm{NCO}]^{+}$and $\left[y_{4}+\mathrm{NCO}\right]^{+}$ions suggests that the isocyanate does not react with the side-chain amine of the arginine residues. Further evidence of binding to the Nterminus is obtained through the observation of the
$[\mathrm{Y}+\mathrm{NCO}]^{+}$immonium ion and an unusual $\mathrm{b}_{1}$ ion. Formation of acylium $b_{1}$ ions is generally considered to result in the loss of $\mathrm{CO}$ to form the stable $\mathrm{a}_{1}$ immonium ion, however, a number of reports have described the formation of stable cyclic $b_{1}$ ions $[26,27]$.

The tandem mass spectrometry data for Substance $P$ amide (RPKPQQFFGLM-NH${ }_{2}$ ) and its PTI and 2,4-TDI adducts are presented in Figure 5. Fragmentation of the $[\mathrm{M}+2 \mathrm{H}]^{2+}$ ion (Figure 5a) is characterized by abundant a- and b-type ions, internal fragment ions containing lysine, and loss of $\mathrm{NH}_{3}$. C-terminal y-type ions are observed in low relative abundance. The isocyanate adducts are localized to the $\mathrm{N}$-terminal arginine residue (Figure $5 \mathrm{~b}$ and $\mathrm{c}$ ), as evidenced by $\left[\mathrm{a}_{1}+\mathrm{NCO}\right]^{+}$and $\left[\mathrm{b}_{1}+\right.$ $\mathrm{NCO}]^{+}$fragment ions. No $\left[\mathrm{y}_{\mathrm{n}}+\mathrm{NCO}{ }^{+}\right.$ions are observed. Of particular note, $\left[\mathrm{y}_{9}+\mathrm{NCO}^{+}\right.$(Lys-containing) and $\left[\mathrm{y}_{1}+\right.$ $\mathrm{NCO}^{+}$(C-terminal Met amide-containing) ions are absent, suggesting no isocyanate adduction at either the 


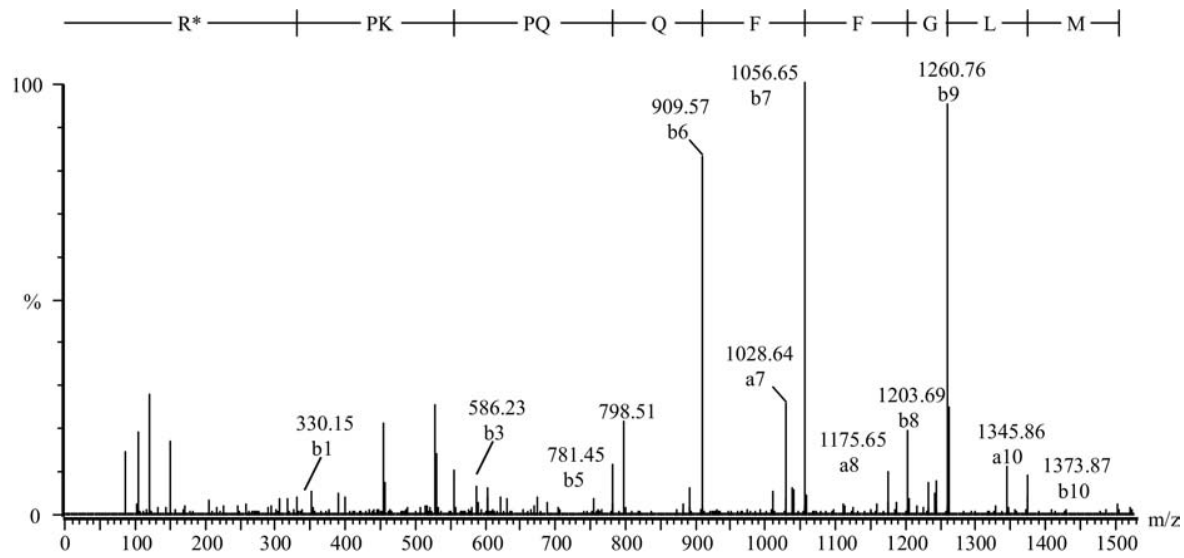

Figure 6. Tandem mass spectrum for Substance P-amide (RPKPQQFFGLM-NH $\left.{ }_{2}\right)+174 \mathrm{u}$ adduct. $\left([\mathrm{M}+2 \mathrm{H}]^{2+} \mathrm{m} / \mathrm{z}=761.3931\right)$.

C-terminal amide or the lysine side-chain at position 3. The most abundant product of the reaction of diisocyanates (2,4-TDI and 2,6-TDI) with Substance $\mathrm{P}$ is the $\left[\mathrm{M}+\mathrm{dNCO}+2 \mathrm{H}^{2+}(+174.0429 \mathrm{u})\right.$ adduct resulting from intramolecular crosslinking. The CID fragment ion spectrum of this ion is presented in Figure 6. The dNCO adduct from the diisocyanate is located on the $\mathrm{N}$ terminal arginine, presumably bound to the N-terminus and an amine on the side chain of arginine. Similarly, a $174 \mathrm{u}$ adduct is observed for the reaction of angiotensin I (which has an arginine at position 2) with diisocyanates (see Tables 2 and 3), although this adduct is observed in low relative abundance. Intramolecular crosslinking via diisocyanates with arginine residues further removed from the N-terminus (FAPP has arginine at positions 5 and 7) is not observed. We interpret this data in aggregate to indicate the diisocyanate rapidly binds to the $\mathrm{N}$-terminal amine and may subsequently react with a side-chain amine of a residue in close proximity. We interpret the relative abundance of these products to indicate that the kinetics of the subsequent side-chain reaction are fast with respect to hydrolysis if the arginine is at position 1, but slow relative to hydrolysis if the arginine is removed to position 2.

Taken as a whole, the present experiments support the findings of Stark [28], who found that the rate of reaction of isocyanates with amino groups is related linearly to $\mathrm{pKa}$. That work suggested that at $\mathrm{pH} 7$ and below, the N-terminus of peptides and proteins would react $\sim 100$ times faster than the $\varepsilon-\mathrm{NH}_{2}$ group of lysine. Furthermore, Stark suggested the reaction proceeds via the uncharged $-\mathrm{NH}_{2}$ species, rather than the $-\mathrm{NH}_{3}{ }^{+}$ ion. The tandem mass spectrometry data presented here supports this hypothesis, as the isocyanate is observed bound preferentially to the N-terminal amine in each peptide. Similarly, Mason and Liebler [29] used phenyl isocyanate at $\mathrm{pH} 8.0$ to label the N-termini of peptides generated by proteolytic digests. Other reports $[13,30]$ have suggested that the N-terminus of proteins (particularly albumin and hemoglobin) is the potential site of diisocyanate adduction, and the results presented here demonstrate conclusively, on the basis of tandem mass spectrometry data, that the $\mathrm{N}$-terminal $\alpha$-amine of these four model peptides is the site of adduction.

\section{Conclusions}

Analysis of peptide-isocyanate adducts by tandem mass spectrometry reveals that isocyanates bind preferentially to the N-terminus of the four peptides examined under the conditions employed herein. When a peptide with an $\mathrm{N}$-terminal residue containing a sidechain amine is reacted with a diisocyanate, intramolecular crosslinking with the second isocyanate becomes competitive with hydrolysis, however, the reactivity decreases as the residue is displaced further from the $\mathrm{N}$-terminus. When the isocyanate-peptide reaction is carried out under 1:1 stoichiometric conditions, the extent of reaction depends on both the choice of isocyanate and peptide. In general, the isocyanate in the ortho position seems to be more reactive than that in the para position. The results of this study, when taken in aggregate with those of previous studies, indicate the N-terminus of proteins is a likely target for adduction in isocyanate-exposed individuals.

\section{Acknowledgments}

The findings and conclusions in this report are those of the author(s) and do not necessarily represent the official position of the Centers for Disease Control and Prevention or the National Institute for Occupational Safety and Health.

\section{Appendix A Supplementary Material}

Supplementary material associated with this article may be found in the online version at doi:10.1016/ j.jasms.2009.04.016. 


\section{References}

1. Randall, D.; Lee, S. The Polyurethanes Book; John Wiley and Sons, Inc.: New York, 2002; pp 63-87.

2. NIOSH. A Summary of Health Hazard Evaluations: Issues Related to Occupational Exposure to Isocyanates, 1989-2002; Department of Health and Human Services, Centers for Disease Control and Prevention, National Institute for Occupational Safety and Health: Cincinnati, OH, 2004.

3. Porter, C. V.; Higgins, R. L.; Scheel, L. D. A Retrospective study of clinical, physiologic, and immunologic changes in workers exposed to toluene diisocyanate. Am. Ind. Hyg. Assoc. J. 1975, 36, 159-168.

4. Adams, W. G. Long-term effects on the health of men engaged in the manufacture of toluylene diisocyanate. Br. I Ind. Med. 1975, 32, 72-78.

5. White, W. G.; Morris, M. J.; Sugden, E.; Zapata, E. Isocyanate-induced asthma in a car factory. Lancet 1980, 1, 756-760.

6. Wisnewski, A. V.; Srivastava, R.; Herick, C.; Xu, L.; Lemus, R.; Cain, H.; Magoski, N. M.; Karol, M. H.; Bottomly, K.; Redlich, C. A. Identification of human lung and skin proteins conjugated with hexamethylene diisocyanate in vitro and in vivo. Am. J. Respir. Crit. Care. Med. 2000, 162, $2330-2336$.

7. Jin, R.; Day, B. W.; Karol, M. H. Toluene diisocyanate protein adducts in the bronchoalveolar lavage of guinea pigs exposed to vapors of the chemical. Chem. Res. Toxicol. 1993, 6, 906-912.

8. Bello, D.; Redlich, C. A.; Stowe, M. H.; Sparer, J.; Woskie, S. R.; Streicher, R. P.; Hosgood, H. D.; Liu, Y. Skin exposure to aliphatic polyisocyanates in the auto body repair and refinishing industry. II. A quantitative assessment. Ann. Occup. Hyg. 2008, 52, 117-124.

9. Petsonk, E. L.; Wang, M. L.; Lewis, D. M.; Siegel, P. D.; Husberg, B. J. Asthma-like symptoms in wood product plant workers exposed to methylene diphenyl diisocyanate. Chest 2000, 118, 1183-1193.

10. Campo, P.; Wisnewski, A. V.; Lummus, Z.; Cartier, A.; Malo, J. L.; Boulet, L. P.; Bernstein, D. I. Diisocyanate conjugate and immunoassay characteristics influence detection of specific antibodies in HDI-exposed workers. Clin. Exp. Allergy 2007, 37, 1095-1102.

11. Johannesson, G.; Sennbro, C. J.; Willix, P.; Lindh, C. H.; Jonsson, B. A. Identification and characterization of adducts between serum albumin and 4, $4^{\prime}$-methylenediphenyl diisocyanate (MDI) in human plasma. Arch. Toxicol. 2004, 78, 378-383.

12. Wisnewski, A. V.; Stowe, M. H.; Cartier, A.; Liu, Q.; Liu, J.; Chen, L.; Redlich, C. A. Isocyanate vapor-induced antigenicity of human albumin. J. Allergy. Clin. Immunol. 2004, 113, 1178-1184.

13. Sabbioni, G.; Hartley, R.; Schneider, S. Synthesis of adducts with amino acids as potential dosimeters for the biomonitoring of humans exposed to toluene diisocyanate. Chem. Res. Toxicol. 2001, 14, 1573-1583.

14. Whitehouse, C. M.; Dreyer, R. N.; Yamashita, M.; Fenn, J. B. Electrospray interface for liquid chromatographs and mass spectrometers. Anal. Chem. 1985, 57, 675-679.

15. Pandey, A.; Mann, M. Proteomics to study genes and genomes. Nature 2000, 405, 837-845.

16. Smith, R. D.; Loo, J. A.; Edmonds, C. G.; Barinaga, C. J.; Udseth, H. R. New developments in biochemical mass spectrometry: Electrospray ionization. Anal. Chem. 1990, 62, 882-899.
17. Cramer, R.; Corless, S. The nature of collision-induced dissociation processes of doubly protonated peptides: Comparative study for the future use of matrix-assisted laser desorption/ionization on a hybrid quadrupole time-of-flight mass spectrometer in proteomics. Rapid Commun. Mass Spectrom. 2001, 15, 2058-2066.

18. Biemann, K. Sequencing of peptides by tandem mass spectrometry and high-energy collision-induced dissociation. In Methods in Enzymology Vol. CXCIII; McCloskey, J. A., Ed. Academic Press: San Diego, CA, 1990; pp 886-887.

19. Chernushevich, I. V.; Loboda, A. V.; Thompson, B. A. An introduction to quadrupole-time-of-flight mass spectrometry. J. Mass Spectrom. 2001, 36, 849-865.

20. Yakabe, Y.; Henderson, K. M.; Thompson, W. C.; Pemberton, D.; Tury, B.; Bailey, R. E. Fate of methylenediphenyl diisocyanate and toluene diisocyanate in the aquatic environment. Environ. Sci. Technol. 1999, 33, 2579-2583.

21. Baur, X.; Belin, L.; Blaska, A.; Dieter, M.; Greenburg, M.; Gut, I.; Mann, M.; Rosenburg, C.; Sakurai, H. Environmental Health Criteria 75: Toluene Diisocyanates; World Health Organization: Geneva, 1987.

22. Lee, F.-T. H. Curatives for Castable Urethane Elastomers. In Handbook of Polymer Science and Technology. Vol II: Performance Properties of Plastics and Elastomers; Cheremisinoff, N. P., Ed. CRC Press: Boca Raton, FL, 1989; pp 291-334.

23. Chipinda, I.; Stetson, S. J.; Depree, G. J.; Simoyi, R. H.; Siegel, P. D. Kinetics and mechanistic studies of the hydrolysis of diisocyanatederived bis-thiocarbamates of cysteine methyl ester. Chem. Res. Toxicol. 2006, 19, 341-350.

24. McLafferty, F. W.; Horn, D. M.; Breuker, K.; Ge, Y.; Lewis, M. A.; Cerda, B.; Zubarev, R. A.; Carpenter, B. K. Electron capture dissociation of gaseous multiply charged ions by Fourier-transform ion cyclotron resonance. I Am. Soc. Mass Spectrom. 2001, 12, 245-249.

25. She, Y. M.; Krokhin, O.; Spicer, V.; Loboda, A.; Garland, G.; Ens, W. Standing, K. G.; Westmore, J. B. Formation of (bn-1 $+\mathrm{H} 2 \mathrm{O})$ ions by collisional activation of MALDI-formed peptide $[\mathrm{M}+\mathrm{H}]+$ ions in a QqTOF mass spectrometer. J. Am. Soc. Mass. Spectrom. 2007, 18, 10241037.

26. Hiserodt, R. D.; Brown, S. M.; Swijter, D. F.; Hawkins, N.; Mussinan, C. J. A study of $\mathrm{b} 1+\mathrm{H} 2 \mathrm{O}$ and b1-ions in the product ion spectra of dipeptides containing N-terminal basic amino acid residues. J. Am. Soc. Mass Spectrom. 2007, 18, 1414-1422.

27. Wysocki, V. H.; Tsaprailis, G.; Smith, L. L.; Breci, L. A. Mobile and localized protons: A framework for understanding peptide dissociation. J. Mass Spectrom. 2000, 35, 1399-1406.

28. Stark, G. R. Reactions of cyanate with functional groups of proteins. 3. Reactions with amino and carboxyl groups. Biochemistry 1965, 4, 1030 1036.

29. Mason, D. E.; Liebler, D. C. Quantitative analysis of modified proteins by LC-MS/MS of peptides labeled with phenyl isocyanate. J. Proteome Res. 2003, 2, 265-272.

30. Sabbioni, G.; Hartley, R.; Henschler, D.; Hollrigl-Rosta, A.; Koeber, R.; Schneider, S. Isocyanate-specific hemoglobin adduct in rats exposed to 4, 4'-methylenediphenyl diisocyanate. Chem. Res. Toxicol. 2000, 13, $82-89$. 